\title{
Placebo, um mal-estar para a medicina: notícias recentes
}

Mônica Teixeira

O artigo relata novos desdobramentos no debate médico a propósito do placebo e seus efeitos, relacionados à sua utilização na clínica médica e em ensaios clínicos de drogas e tratamentos.

Palavras-chave: Placebo, efeito placebo, ensaios clínicos, clínica médica 
A ciência permanece ignorante sobre a natureza do efeito-placebo e as razões de sua eficácia. Nem por isso os médicos, em sua prática clínica, renunciam a utilizar seu poder de cura e alívio. É o que se constata da leitura do artigo "Receitando 'tratamentos placebo’: resultado de uma enquete nacional com clínicos e reumatologistas norte-americanos", publicado em outubro de 2008 pelo ex-British Medical Journal (agora simplesmente $B M J$ ), que concentra a atenção de “Observando a Medicina” nesta última edição de 2008. O artigo se baseia nos resultados de uma enquete enviada a 1,2 mil médicos dos Estados Unidos.

Não é certamente a primeira vez que a seção se entretém com o mal-estar causado pelo placebo à medicina "baseada em evidências”. Em "Sobre placebo e efeito placebo" (Plessmann de Camargo; Teixeira, 2002), a Revista apresentou dados compilados em seminário patrocinado pelos National Institutes of Health, que testemunhavam a resistência do placebo ao 'arsenal' usual da ciência da medicina. No mesmo campo do trabalho do NIH, uma revisão de 2008, do neurocientista Fabrizio Benedetti, da Universidade de Turim, reúne o conhecimento existente sobre o efeito que a administração de placebo apresenta sobre a bioquímica cerebral.

Não há, no entanto, uma explicação científica abrangente, aceita pelo establishment da medicina, para os mecanismos e os efeitos do placebo. Essa dificuldade coloca um paradoxo: as evidências em que a medicina contemporânea baseia a prescrição dos tratamentos standards são obtidas por meio de experimentos controlados, nos 
quais quem fornece a contra prova da eficácia do tratamento são placebos e seus efeitos. Nos casos em que há um tratamento já recomendado, é contra ele que o novo tratamento é testado. Esse tratamento original, no entanto, ou o anterior a esse, foi também testado contra placebo. O medicamento "provado", os cientistas pensam saber como age e de onde retira sua eficácia; mas, e sobre o placebo?

É esse paradoxo que atrai o interesse da seção para a questão. No trimestre em que esta edição da Revista foi preparada, a palavra placebo freqüentou a mídia quando da publicação do artigo sobre seu uso comum por clínicos; e pelo menos outras duas vezes. Em sua edição de 23 de agosto, a revista New Scientist relatou certas travessuras dos placebos - por exemplo, o fato de que o efeito do diazepam no pós operatório só ocorre se o operado souber que está tomando diazepam. O jornalista Michael Brooks escreveu seu texto em torno da observação de que o efeito placebo “arruína” a credibilidade da medicina - uma afirmação do neurocientista Benedetti. O artigo da New Scientist ressalta uma mudança de abordagem: os cientistas ouvidos agora admitem a complexidade do efeito placebo, reconhecem que ele se estende a qualquer medicamento ministrado por médicos, e pretendem descobrir de que maneira incorporar seus efeitos para beneficiar a medicina baseada em evidências.

Uma linha de investigação mais difundida a propósito do placebo e seus efeitos, no enquadre da medicina científica, é aquela que pretende saber sobre a ética de seu uso. Em outubro de 2008 - e esta foi a terceira menção a placebos registrada pela seção -, a Associação Médica Mundial, reunida em assembléia em Paris, mudou o texto do artigo 32 da Declaração de Helsinque, que regula a participação de seres humanos na pesquisa clínica (aquela que testa os futuros tratamentos em humanos, por oposição aos testes pré-clínicos, em que animais são utilizados). A norma vigente até a assembléia de outubro vetava a possibilidade do uso de placebo em ensaios clínicos, quando há outro tratamento disponível. A diretriz pretendia impedir, explicou o jornal O Estado de S. Paulo, que as companhias farmacêuticas (capazes de tudo por dinheiro, um entendimento bastante apreciado e difundido pela mídia) lançassem mão do placebo como forma de diminuir os custos dos ensaios clínicos de suas drogas.

No novo texto do artigo 32, “o uso de placebo, ou o não-tratamento" recebeu a qualidade de "aceitável” quando, para a doença estudada, não existir current proven intervention, como se diz em inglês. Acrescenta-se que o placebo pode passar a ser utilizado quando se mostrar necessário por "razoes metodológicas sensatas”, e na ausência de "risco de dano sério ou irreversível” para os pacientes - mas sob severa vigilância e controle. É uma volta ao passado: até a década de 1960, quando o protocolo de Helsinque foi instituído, não havia restrição ao uso do placebo na prática clínica ou durante experimentos. 
A idéia de que o ser humano envolvido em um experimento deve ser protegido do uso do placebo baseia-se na concepção do placebo como "substância inócua”. É porque o placebo é “inócuo” que, para a bioética, não se pode utilizá-lo quando há outro tratamento disponível - seria como negar socorro, o que contraria a exigência de que a participação em um ensaio clínico não traga dano ao paciente.

Inócuo, placebo não é. A repetição dessa qualificação, a falta de uma explicação satisfatória dentro do campo da medicina científica para seu poder, ou a condenação vinda da Bioética, nada disso impede que médicos continuem a utilizar o placebo. O resultado da enquete publicada no $B M J$, sobre a prescrição de placebo entre reumatologistas e clínicos dos Estados Unidos, mostra que, entre eles, o placebo se integra à prática da medicina como o que é: um tratamento eficiente, se ancorado na relação entre o médico e aquele que o procura em busca de alívio.

\section{O placebo na prática clínica de reumatologistas e internistas}

Os autores do artigo "Prescribing 'placebo treatments': results of national survey of US internists and rheumatologists" são conhecidos participantes das discussões sobre placebo e medicina: Jon Tilburt e Ezekeil Emanuel, do departamento de Bioética do National Institutes of Health, a principal agência de fomento à pesquisa em medicina do mundo, com sede em Bethesda, nos EUA; Ted Kaptchuk, da Escola de Medicina de Harvard; Farr Curlin e Franklin Miller, da Universidade de Chicago. Para realizar a pesquisa que relatam, os autores enviaram um questionário a 1,2 mil clínicos e reumatologistas em atividade nos Estados Unidos para avaliar "atitudes e comportamentos referentes a tratamentos com placebo". Foram obtidas respostas de 679 médicos.

A maior parte deles (46\% quando a palavra placebo foi utilizada na pergunta, $58 \%$ quando o tratamento por placebo foi descrito sem a menção da palavra) incorpora o placebo em sua prática 'em bases regulares'; em geral, consideram seu uso eticamente permissível. Poucos médicos prescrevem soluções salinas ou pílulas de açúcar, como no passado - preferem, ao contrário, prescrever como placebo vitaminas ou analgésicos que dispensam receita; e um número "pequeno, mas notável” prefere prescrever antibióticos (13\%) ou sedativos (outros $13 \%)$. Ao prescrever o placebo, 68\% dos médicos informam ao paciente que o tratamento recomendado é "potencialmente benéfico” mas não "tipicamente utilizado” para casos como o do paciente em questão. 


\section{O que é efeito placebo}

Na introdução, os autores observam que o conceito de "tratamento com placebo" é obscuro e complicado, e que falta "uma definição padrão”. Para efeito do estudo, definem um tratamento com placebo aquele em que os "benefícios (na opinião do clínico) derivam de expectativas positivas do paciente e não do mecanismo fisiológico do próprio tratamento". A leitura da introdução é útil para lembrar que já há registros de atenção ao placebo e seus efeitos pela medicina da segunda metade do século XIX; e que seu uso era lugar-comum até o desenvolvimento de "intervenções farmacêuticas efetivas" e a "ênfase crescente" no consentimento informado (é obrigatório, quando do engajamento de pacientes em experimentos clínicos, que eles sejam informados claramente sobre riscos e procedimentos e concordem com essas condições). A partir da década de 1960, afirma o paper, o entendimento predominante muda. De acordo com os autores, a prescrição de placebo envolve "burlar a confiança" do paciente e, por isso, violaria a autonomia do paciente e a regra do consentimento informado. Apesar da "persistente controvérsia", dizem os autores, pouco se fez para investigar a atitude dos clínicos, em sua prática, em relação ao assunto.

\section{Quem respondeu à enquete}

Clínicos e reumatologistas foram os escolhidos como alvo da enquete por tratarem comumente, nas palavras do $B M J$, com pacientes que sofrem de doenças crônicas e debilitantes, “de manejo notoriamente difícil”. Os questionários foram enviados em junho de 2007. Um incentivo de 20 dólares era oferecido, como uma recompensa pela participação voluntária. Entre os que responderam (57\% do total), 334 eram clínicos de medicina interna (56\%) e 345 reumatologistas (58\% da amostra).

\section{Como os pesquisadores tentaram evitar viéses}

As questões sobre placebo foram incorporadas a um questionário maior, sobre medicina alternativa. Deliberou-se iniciar o questionário com perguntas genéricas, em que a palavra placebo não aparecesse. As questões ganhavam gradativamente maior especificidade, até chegar a apresentar uma definição clara de tratamento com placebo. O primeiro conjunto de três perguntas apresentava ao respondente um cenário hipotético, em que o tratamento com uma cápsula de 
dextrose apresentava, em ensaio clínico, desempenho superior à opção de não aplicar nenhum tratamento. Os participantes eram então chamados a responder qual a probabilidade de eles prescreverem a cápsula de dextrose para pacientes nãodiabéticos com fibromialgia; com que freqüência recomendam um tratamento primariamente para aumentar as expectativas do paciente de melhorar; e se recomendar um tratamento por esses critérios era "obrigatório”, "permissível”; "permissível em raras circunstâncias” ou "nunca permissível”. O passo seguinte era perguntar quais tratamentos foram usados por eles, no ano anterior, como tratamentos-placebo, de acordo com a definição apresentada e de que maneira informavam aos pacientes sobre o tratamento-placebo.

\section{A razão dos médicos}

$\mathrm{O}$ fato de tantos médicos afirmarem que utilizariam um tratamento-placebo para tratar fibromialgia no cenário em que a pílula de açúcar traria melhora em relação a nenhum tratamento, não é a maior descoberta da pesquisa - isto confirma estudos anteriores. Para os autores, a mais intrigante "questão não-resolvida” levantada pelo estudo foi descobrir que os médicos utilizam, como placebos, não substâncias inativas - como a pílula de açúcar ou uma solução salina -, mas substâncias ativas como vitaminas, analgésicos que dispensam receita, antibióticos ou sedativos.

Os autores apontam a dificuldade de obtê-las como uma possível causa para a baixa prescrição de pílulas de açúcar ou solução salina. Conjeturam também que o médico pode se sentir enganando mais ativamente seu paciente pela indicação de uma pílula com substância completamente inativa; ou, ainda, que dessa maneira sua ação atinge com mais intensidade a regra do consentimento informado. Com tudo isso, os autores do artigo não se mostram desconfortáveis. Mas a decisão pela prescrição de antibióticos e sedativos - essa, sim, uma descoberta do estudo - os preocupa, por poder trazer "conseqüências adversas importantes para pacientes e para a saúde pública”.

\section{Quem sabe? O estudo não!}

Sobre a motivação principal que leva clínicos a aprovarem a administração de tratamento-placebo e se utilizarem dela, o estudo apresenta hipóteses. Na base, acreditam, para esses clínicos e reumatologistas, estaria o desejo de criar a ex- 
pectativa no paciente de que ele vai melhorar. Há uma percepção geral, informa o texto, da necessidade "de ministrar alguma coisa na ausência de outros tratamentos efetivos para condições sintomáticas crônicas”. Já sobre a decisão de escolher antibióticos ou sedativos fora de suas indicações canônicas - aquelas sancionadas pela medicina baseada em evidências -, o estudo não avança e pede mais investigações, que “Observando a Medicina” pretende acompanhar.

\section{Referências}

Benedetti, F. Mechanisms of Placebo and Placebo-Related Effects across diseases and treatments. Annu. Rev. Phamacol. Toxicol., Palo Alto, CA, n. 48, p. 33-60, 2008.

Brooks, M. The Power of Belief. New Scientist, p. 36-39, 23 de agosto de 2008.

Plessman de Camargo, E.; Teixeira, M. Sobre placebo e efeito placebo. Revista Latinoamericana de Psicopatologia Fundamental, São Paulo, v. V, n. 2, p. 118-125, jun. 2002.

PRESCRIBING "placebo treatments": results of national survey of US internists and rheumatologists. BMJ 2008 337a1938. Disponível em: <http://www.bmj.com>. Acesso em: 2 nov. 2008.

World Medical Association Declaration of Helsinki. Disponível em: <http:// www.wma.net/e/policy/pdf/17c.pdf>. Acesso em: 23 out. 2008.

\section{Resumos}

(Placebo, un malestar para la medicina: noticias recientes

El artículo resalta nuevos desdoblamientos en el debate médico a propósito del placebo e sus efectos relacionados a su utilización en la clínica médica y en ensayos clínicos de drogas y tratamientos.

Palabras claves: Placebo, efecto placebo, ensayos clínicos, clínica médica

(Placebo, un malaise pour la médecine: nouvelles récentes)

Cet article porte sur les nouveaux résultats du débat médical sur les placebos et leurs effets par rapport à leur utilisation en clinique médicale et dans des essais cliniques de médicaments et traitements.

Mots clés: Placebo, effet placebo, essais cliniques, clinique médicale 
(Placebos, a problem for medicine: recent news)

This article discusses new perspectives in the medical debate on the effects of placebos. Aspects related to their use in medical clinical work and in writings on drugs and treatment are also taken up.

Key words: Placebos, placebo effects, clinical writing, medical clinical work

Versão inicial recebida em novembro de 2008 Versão aprovada para publicação em novembro de 2008

\section{MôNICA TeIXEIRA}

Jornalista; psicanalista; coordenadora geral do programa Universidade Virtual do Estado de São Paulo na TV Cultura (São Paulo, SP, Brasil); diretora de redação do boletim eletrônico Inovação Unicamp (Campinas, SP, Brasil).

Av. Higienópolis, 318/13

01238-001 São Paulo, SP, Brasil

e-mail: armonica@uol.com.br 